\title{
Solid form changes during drug development: good, bad, and ugly case studies
}

\author{
Ann Newman ${ }^{1,2^{*}}$ and Robert Wenslow ${ }^{2}$
}

\begin{abstract}
The relevance of solid form in drug development has been well established over time. In order to fully understand drug properties, attention has been paid to solid state structure of drug molecules and their relationship to the drug formulation. While each drug developer has had their own strategies and workflows for screening and choosing solid forms of drug molecules, the industry is aware of instances where "the best laid plans" often go awry. This manuscript has summarized several case studies in development programs that display the "good, bad, and ugly" of solid form changes.
\end{abstract}

Keywords: Solid forms, Crystalline forms, Amorphous materials, Polymorphs, Salts, Cocrystals, Amorphous solid dispersions, Case studies

\section{Background}

It has been reported that the solid form of active pharmaceutical ingredients (APIs) has significantly impacted quality and consistency of the final dosage form for drug development compounds (Newman and Byrn 2003), especially for solid oral dosage formulations. Therefore, monitoring and controlling the API solid form in both drug substance and drug product has been recommended in order to ensure consistent biopharmaceutical properties throughout a drug development program.

Every innovator drug developer has approached API solid form decisions with a unique paradigm; however, identifying and maintaining the optimal API solid form in early pharmacokinetic studies, as well as maintaining this form through product launch, has been recognized as an ideal situation. This utopian scenario, however, has often been noted to be far removed from reality, especially if the API solid form has been ignored or assumed to be trivial for a particular program. This has often led to significant program delays and cost as bioequivalence studies, new crystallization studies, or formulation development may have been needed.

\footnotetext{
* Correspondence: ann.newman@seventhstreetdev.com

${ }^{1}$ Seventh Street Development Group, Kure Beach, NC 28449, USA

${ }^{2}$ Crystal Pharmatech, New Brunswick, NJ, USA
}

This manuscript presents the "good, bad, and ugly" aspects of API solid form changes in the pharmaceutical industry. It has explored and elaborated upon specific case studies that outline the impact of API solid form changes brought about by choosing a non-ideal salt form for early preclinical development, relaxed due-diligence for a "fast-tracked" compound, a serendipitous late stage form change, lack of attention to solid form for an inlicensed compound, and a less than bullet-proof intellectual property (IP) landscape surrounding an innovator molecule.

The goal of these examples was to show that adequate attention to API solid form during development will aid in managing risk for a program. Whether an innovator company was looking to out-license a gold molecule as a platinum package, an innovator company was looking to bring a drug to market with a strong patent landscape, or a generic company was looking to enter the market with IP for their molecule, the case studies presented in this manuscript clearly show that API solid form is an important aspect of any development program.

The case studies presented, in addition to many other un-published examples, have confirmed to pharmaceutical scientists that no screening strategy can guarantee that all crystal forms have been discovered. However, appropriate attention to API form and a sound screening

\section{至 Springer}




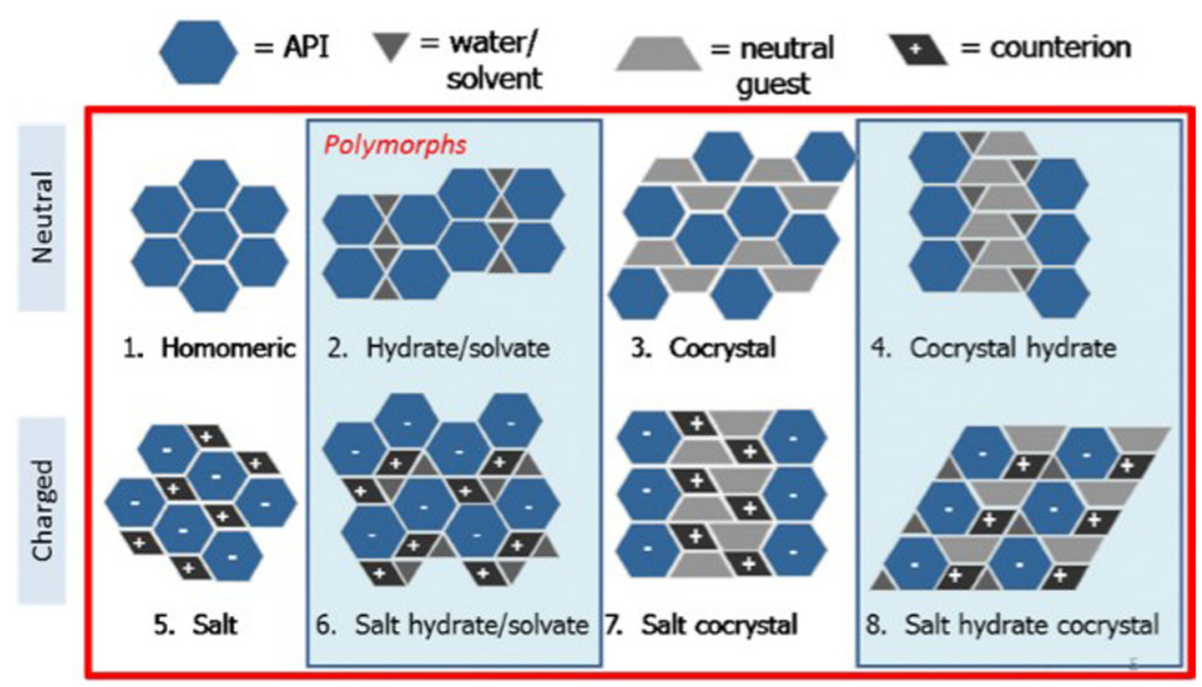

Fig. 1 Classification of crystalline API forms. The red box signifies that polymorphs of all solid form classes are possible; the blue boxes represent classes containing hydrates

strategy has had the potential to mitigate the risk for form changes in the API and drug product.

Solid forms have been defined as both crystalline and amorphous materials in this paper. Crystalline forms have been sub-classified into categories outlined in Fig. 1, and described as neutral (such as free forms and cocrystals) and charged (salts or salts of co-crystals) species. Each category of crystalline materials has the possibility of displaying polymorphism (solvates and hydrates have been included in our polymorph classification based on the regulatory definition). Any material from the crystalline API categories that lacks long range order as characterized by $\mathrm{x}$-ray powder diffraction (XRPD) has been referred to as amorphous API.

\section{Case studies}

Indinavir - early salt form change

Indinavir sulfate, marketed as Crixivan ${ }^{\circ}$ (Fig. 2), was approved in 1996 as a human immunodeficiency virus type 1 (HIV-1) protease inhibitor indicated for treatment of HIV infection and AIDS in adults (Lin 1999; Lin et al. 1998; Crixivan Package Insert. (available at http://www.merck.com/product/usa/pi_circulars/c/crixi van/crixivan_pi.pdf. Accessed 23 Feb 2016). Crixivan ${ }^{\circ}$ was initially developed as a free base monohydrate, but suffered from significant $\mathrm{pH}$ dependent solubility (Fig. 3) and limited adsorption as the free base form (Lin et al. 1998). As a result, a need to identify an acceptable, soluble salt for clinical dosage development arose for researchers. The $\mathrm{pH}$ solubility profile and $\mathrm{pKa}$ of the molecule suggested a rather acidic salt was necessary to achieve complete dissolution. One issue, however, was that Crixivan ${ }^{\circ}$ was quite unstable in acidic solutions (Table 1), which presented a stability risk for solid salt forms (Lin et al. 1998). The crystalline sulfate salt ethanolate was chosen as the lead salt form for development. The aqueous solubility for this salt form was in excess of $500 \mathrm{mg} / \mathrm{ml}$ with a resulting solution $\mathrm{pH}$ of $<3$. The main concern for the sulfate salt ethanolate was the excessive hygroscopicity (Fig. 4). Additionally, the ethanolate had the potential to change physical form at elevated humidity, even potentially going amorphous. Because of this, extensive solid-state stability and excipient compatibility studies were performed using controlled humidity conditions. Experiments showed that a shelf life of $>$ 2 years was possible when the humidity was kept $<$ $30 \%$ relative humidity $(\mathrm{RH})$, even for the amorphous sulfate salt. At temperatures and humidity above $40^{\circ}$ $\mathrm{C}$ and $30 \% \mathrm{RH}$ respectively, the sulfate salt suffered from rapid degradation for both the API and drug product. Because of the need for low $\mathrm{RH}$, a dry granulation formulation process was developed for the drug product (Lui et al. 2003). Human clinical trials were conducted with both the sulfate salt ethanolate

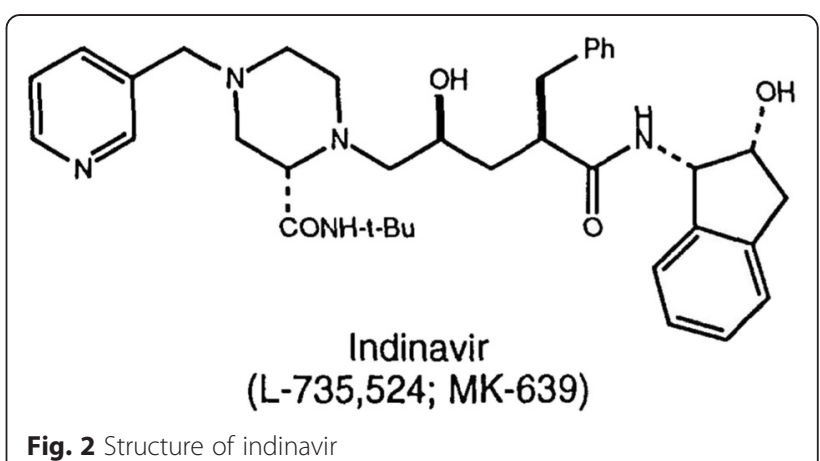




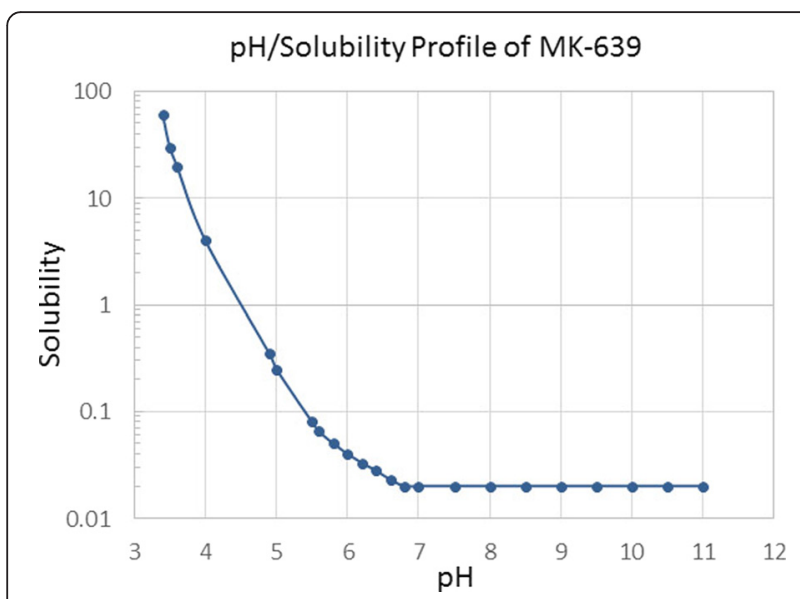

Fig. $3 \mathrm{pH}$ solubility profile of indinavir (adapted from Ref (Lin et al. 1998))

and free base monohydrate (Yeh et al. 1998). The study showed that the sulfate salt in the fasted state or with a low fat meal yielded the highest exposures (Fig. 5).

This example has clearly displayed the utility of identifying the appropriate salt form before clinical trials have been initiated and has also represented a "good" scenario for solid form in development. This case study has presented a classic example of solid state form impacting pharmacokinetic profiles of a drug. The example has also shown that relatively poor physicochemical properties can be mitigated with a thorough understanding of both chemical and physical stability profiles. The sulfate salt ethanolate displayed excessive hygroscopicity and form change potential; however, processing and storage conditions were identified to successfully process and store API and drug product.

\section{DPC 961 - Form change on a fast track compound}

DPC 961 (Fig. 6) was a development compound indicated for the treatment of HIV infections and was developed as a neutral molecule (Staszewski et al. 1999). The compound was designated as Biopharmaceutics Classification System (BCS) II, with high permeability, low aqueous solubility and therefore would display dissolution limited behavior (Aungst et al. 2002). As a result, physicochemical characteristics such as particle size, crystal form, and surface area may have had a direct impact on bio-performance. Early in development, this compound had been known to exist in many solvated forms in addition to a single, anhydrous crystal form (Form I) (Desikan et al. 2005). Preliminary screening work had never identified crystallization solvents that directly isolated Form I. All pathways to Form I involved forming a solvate and then de-solvating to obtain Form I. The first 29 development batches of DPC 961 involved isolation of the API through crystallization from toluene/heptane, followed by re-crystallization from methanol $(\mathrm{MeOH})$. Anhydrous Form I was the product in all 29 batches; however, this form was not directly crystallized, but instead, formed through de-solvation of the stoichiometric $\mathrm{MeOH}$ solvate by elevated temperature drying. On the $30^{\text {th }}$ batch, a lower melting crystal form, anhydrous Form III, was the product. Form III was determined to be enantiotropically related to Form I, with Form III being the low temperature stable polymorph with transition temperature between 120 and $174{ }^{\circ} \mathrm{C}$, as determined from DSC data using Burger's rules. A van't Hoff investigation had not been performed in this polymorph system, presumably since no solvent had been found that had not formed a solvate with either Form I or III.

After the serendipitous discovery of Form III, Form I was never again manufactured at large scale. When the desolvation employed in the first 29 batches was attempted after Form III was discovered, the product was now Form III, and not Form I. Form I had been prepared on small scale by heating Form III above melting point, but a manufacturing process could not be developed. This circumstance was a clear example of the phenomenon labeled as a "disappearing polymorph" (Dunitz and Bernstein 1995). Due to this change in form, researchers were now left with Form III. Since the compound was BCS II, dissolution may have critically impacted bioperformance. Thus, the first set of experiments necessary when Form III was discovered and realized to be the future chosen phase was to understand bio-relevant dissolution and solubility. Fortunately, Form III had comparable aqueous solubility and intrinsic

Table 1 pH Stability Data for Indinavir (used with permission from Ref (Crixivan Package Insert. (available at http://www.merck.com/ product/usa/pi_circulars/c/crixivan/crixivan_pi.pdf. Accessed 2 March 2015))

\begin{tabular}{llll}
\hline $\mathrm{pH}$ & Buffer & $\mathrm{k}_{1}\left(\mathrm{hr}^{-1}\right)$ at $40{ }^{\circ} \mathrm{C}$ & $\mathrm{t}_{1 / 2}(\mathrm{days})$ at $40{ }^{\circ} \mathrm{C}$ \\
\hline 1 & $0.1 \mathrm{M} \mathrm{HCl}$ & $2.16 \times 10^{-3}$ & 13 \\
2 & $0.1 \mathrm{M}$ maleate & $1.14 \times 10^{-3}$ & 25 \\
3 & $0.1 \mathrm{M}$ citrate & $7.12 \times 10^{-4}$ & 41 \\
4 & $0.1 \mathrm{M}$ citrate & $3.36 \times 10^{-4}$ & 86 \\
5 & $0.1 \mathrm{M}$ citrate & $1.10 \times 10^{-4}$ & 262 \\
11 & $0.1 \mathrm{M}$ carbonate $\left(1 / 1 \mathrm{MeOH} / \mathrm{H}_{2} \mathrm{O}\right)$ & $1.23 \times 10^{-3}$ & 23 \\
\hline
\end{tabular}




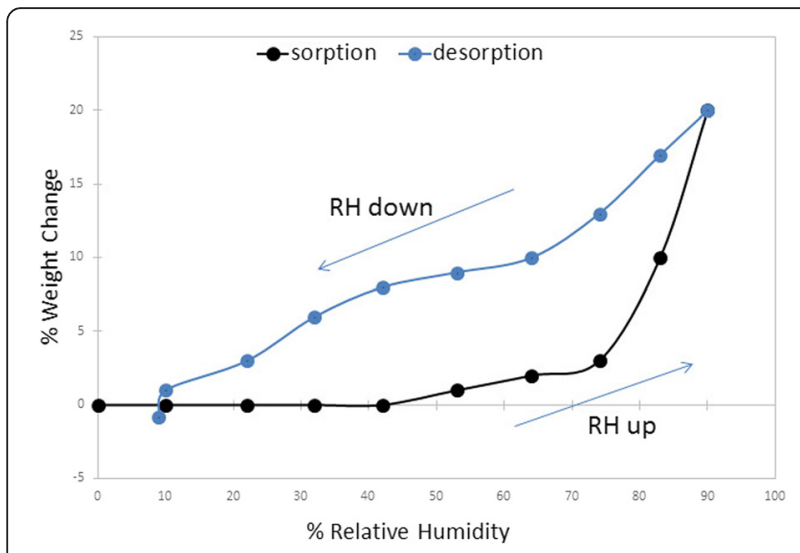

Fig. 4 Water sorption/desorption profile of indinavir (adapted from Ref (Lin et al. 1998))

dissolution rates. An oral absorption study in animals was necessary to confirm that bio-performance would not be impacted by the crystal form change. When Form I and Form III were formulated into tablets and orally administered to dogs at $100 \mathrm{mpk}$, the oral absorption profiles were statistically identical (Fig. 7). If this had not been the case, and formulated Form I resulted in a unique absorption profile compared to Form III, a human bridging study would have been necessary. The cost and program delays would have been substantial. While statistics are not available, the chances of Form III and Form I having identical bio-performance for a BCS II compound was likely to be low. The more probable result would have been distinct solubility and/or dissolution differences between the polymorphs. Even though a clinical bridging study was not necessary after the polymorph change, the research team still had to develop a unique API isolation process and update analytical methods, in addition to providing the necessary data to prove polymorph stability and bio-equivalence, which would have likely taken a minimum of six months to perform.

The lessons learned from this case study would vary based on the company's risk-management strategy. It has been generally accepted that isolating the final crystal form through desolvation would be a non-ideal process; rather, a process where the final form has been directly nucleated and grown (with or without seeds) would be preferred. However, there have been compounds that, when developed initially, have only appeared to form solvates. These solvates may or may not have had the potential to de-solvate to a physically stable anhydrous crystal form. In this case study, Form I

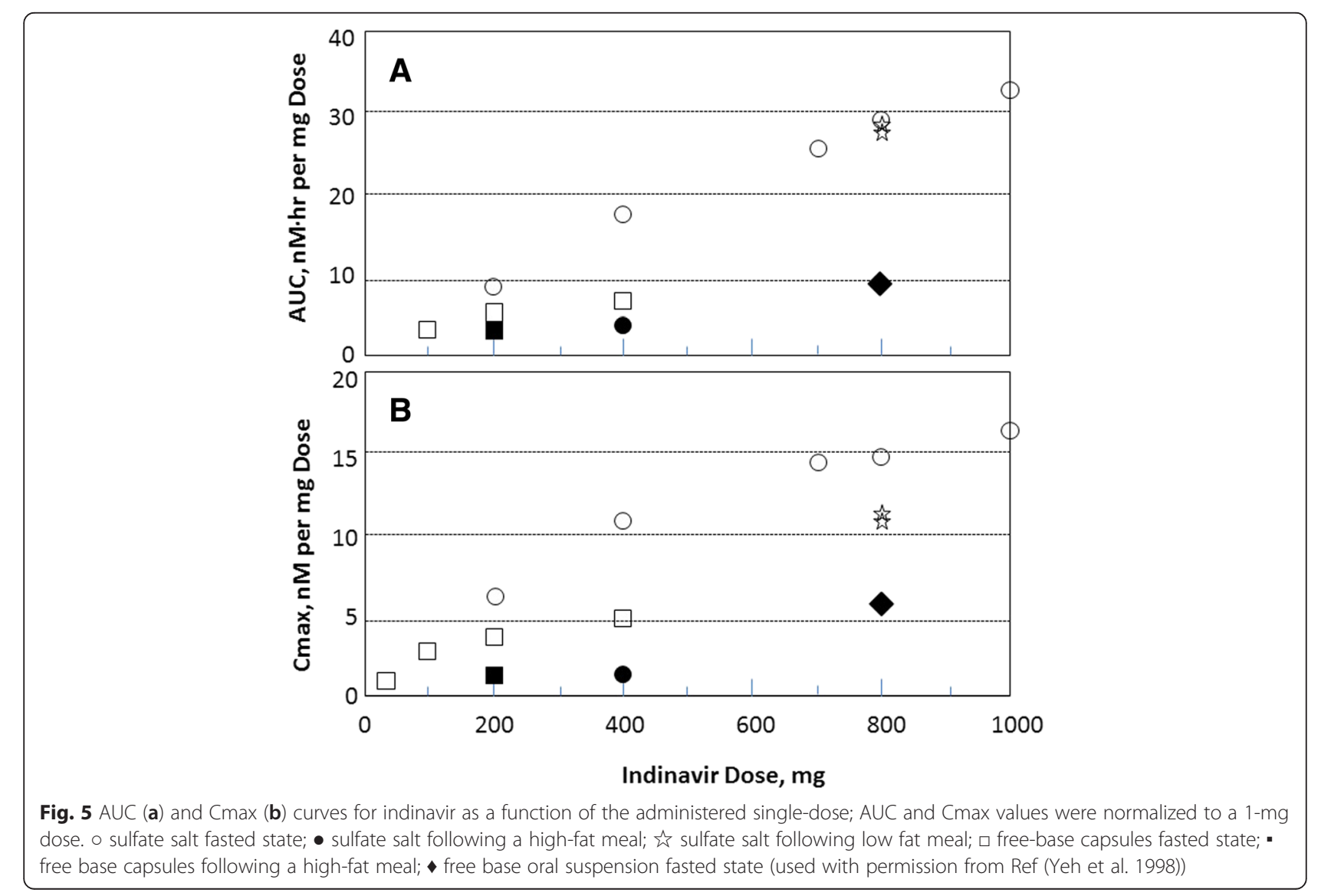




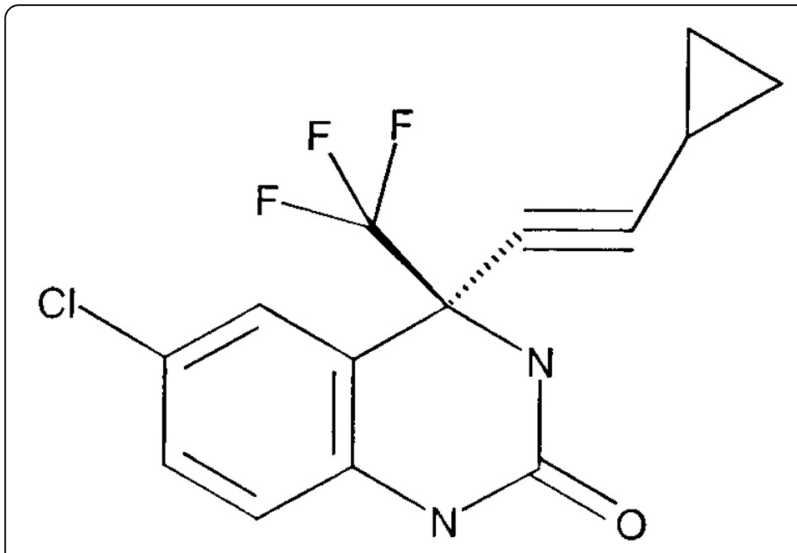

Fig. 6 Structure of DPC 961

appeared to exhibit adequate physical stability, but was not found to be an anhydrous crystal form that could have been directly nucleated and grown in an appropriate solvent system. Due to the speed of the program, it could have easily been argued that the process was robust in isolating Form I, as 29 batches had been completed without incident. The opportune discovery of Form III may have occurred due to a variety of causes including, but not limited to: impurity differences (either level or actual type of impurities) in the process stream, unique levels of supersaturation, or foreign particle providing heteronuclear templates for nucleation. It is not known whether extensive screening early in the program would have uncovered Form III. However, many compounds that have only been isolated as a solvate had

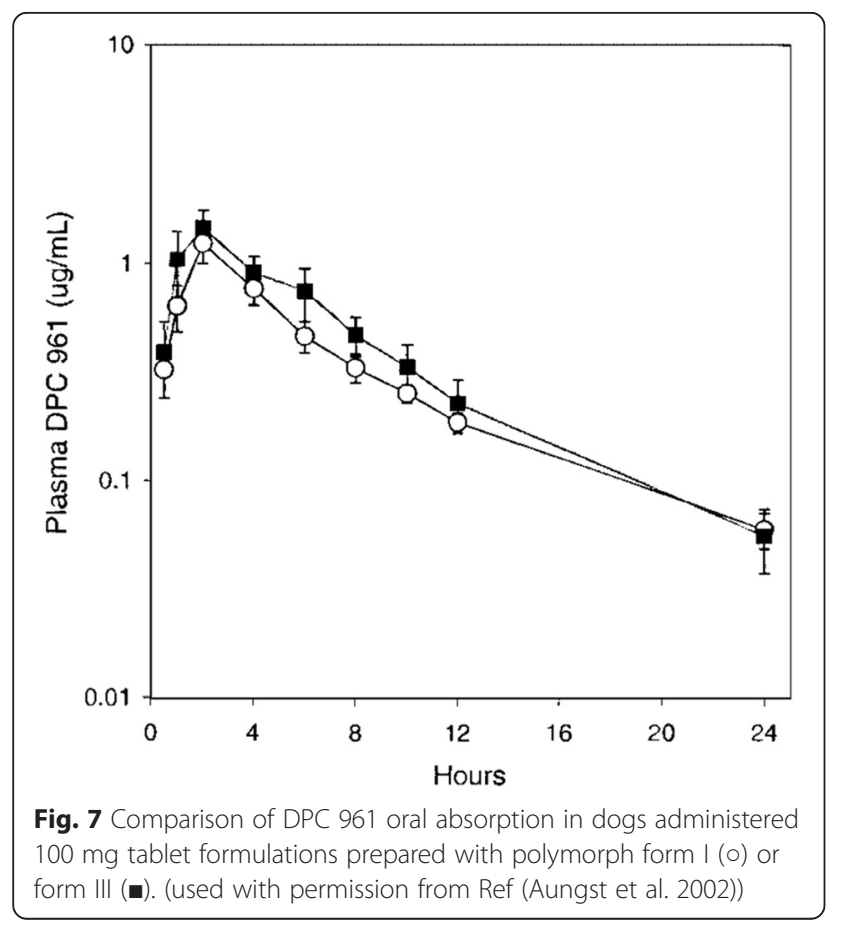

often times masked an anhydrous crystal form that had been anticipating the right trigger in order to be discovered. Therefore, an appropriate and diligent level of crystal form screening should be applied to this type of compound, especially since the compound was designated at BCS II. The screening strategy should have involved conditions attempting to avoid solvate formation (Campeta et al. 2010). This "fast-track" compound could be deemed a "bad" scenario when the time delays and increased costs to the project have been added to the development plan.

\section{Atorvastatin - crystalline form change in late development}

Atorvastatin (CI-981) is an HMG CoA reductase inhibitor marketed as Lipitor ${ }^{\circledR}$ (Fig. 8). As a BCS II drug, it has exhibited poor solubility and high permeability (Wu and Benet 2005). The compound was originally discovered at Warner-Lambert in the 1980's, and the amorphous form of the hemi calcium salt pure enantiomer was used for early clinical trials. Phase 1 studies were conducted by the Parke-Davis Clinical Research Unit (CRU) recruiting twenty-four (24) males from within the company (Lie 2009). Phase 2 clinical trials showed an improvement in performance when compared to data from four marketed drugs (Fig. 9). Priority review status was requested in 1994, but was denied because the drug had not met an unmet medical need. The company proceeded to fund a clinical study for familial hypercholesterolemia, where the compound showed efficacy, and they were granted priority review status which helped to shorten the development time. Atorvastatin calcium was approved by the Food and Drug Administration (FDA) in late 1996.

The only known solid form for atorvastatin calcium in Phase 1 and 2 clinical trials was the amorphous form. It exhibited poor filtration and drying characteristics for large scale batches and required protection from heat, light, oxygen, and moisture (Briggs et al. 1999). During Phase 3 clinical trials, a crystalline form was produced at scale which was determined to be a trihydrate and referred to as Form I (Briggs et al. 1999). This crystalline form possessed a number of advantages over the amorphous form including higher purity, improved

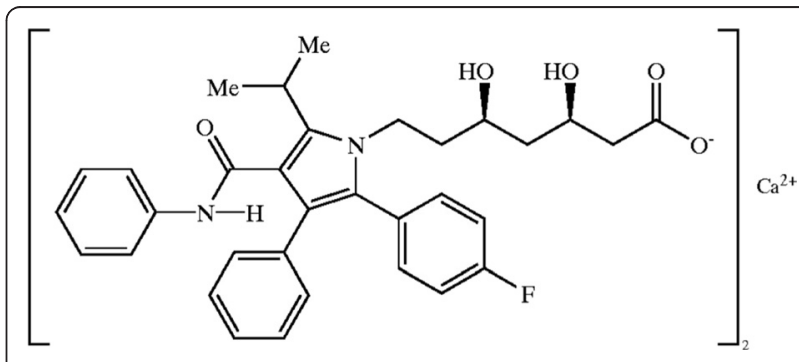

Fig. 8 Structure of atorvastatin 


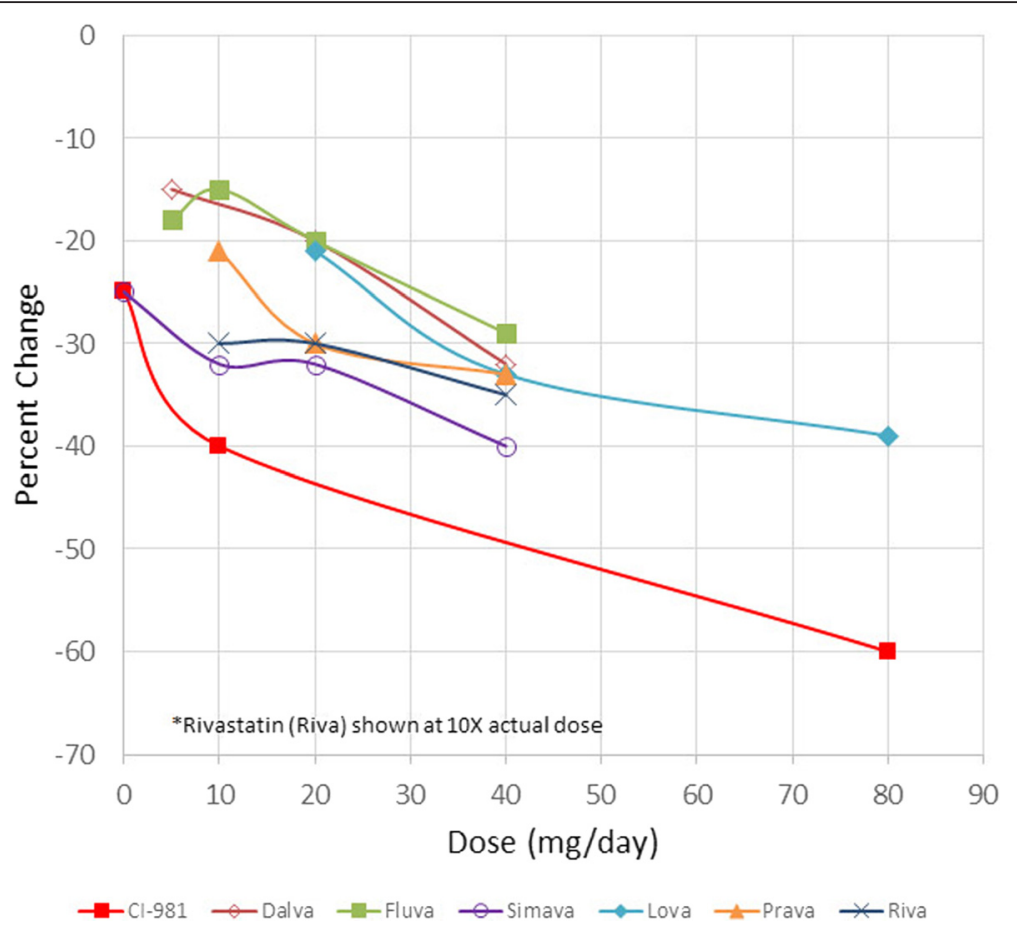

Fig. 9 Atorvastatin (Cl-981) Phase II results compared with marketed products (adapted from Ref (Lie 2009))

chemical stability, tighter uniformity in particle size distribution, and better filtration and drying properties. While finding a new form at this stage of development would normally be undesirable, the improvements gained with the new crystalline form were substantial enough for researchers to change the solid form during late development. All aspects of the project needed to be repeated, such as the API manufacturing process development, formulation development, stability studies, analytical methods, and human bioequivalence testing. Tablets produced with amorphous and crystalline trihydrate atorvastatin calcium showed a difference in the rate of absorption, but equivalent extent of absorption in the bioequivalence test (Pfizer Citizen Petition. Docket no 2005P).

Other crystalline forms were patented along with Form I (designated Forms II and IV) (Briggs et al. 1999), and additional forms followed in subsequent patent applications (Byrn et al. 2003; Tesslor et al. 2003; Van Der Schaaf et al. 2009). The next challenge for the team was to develop a crystallization process that produced uniquely Form I with the desired characteristics they needed. One patented process reported that adding methyl-t butyl ether (MTBE) to the reaction mixture after forming the salt, followed by subsequent seeding, had produced the desired Form I (Tully 2003).

The FDA orange book has listed a number of patents for atorvastatin calcium, including the composition of matter patent (expired September 24, 2009), a salt patent including the calcium salt (expired Dec 28, 2010), and the crystalline Form I patent (expires July 8, 2016). By using a form other than Form I, generic products were technically allowed on the market in 2010. After numerous legal battles and an agreement between Pfizer and Ranbaxy, the generic version of Lipitor ${ }^{\circ}$ was available in late 2011 (Lie 2009).

The atorvastatin story has covered a number of teaching points regarding solid forms. Polymorph screens were not routinely performed when atorvastatin was under development and it was common to find forms during scale-up, especially when conditions were changed. In the case of atorvastatin, a screen was performed after the crystalline form was found and a number of forms were produced, based on the patent literature (Briggs et al. 1999; Byrn et al. 2003; Tesslor et al. 2003; Van Der Schaaf et al. 2009). In present day cases, a solid form screen should be performed in early development to find a suitable form long before Phase 3 clinical trials. An earlier solid form screen would also have prevented the repeat of major studies late in development, as seen when atorvastatin Form I was found. Screening studies do not guarantee that all forms have been found, but they have significantly reduced the risk for most programs. The patents listed in the Orange Book and the strategy of using patents to maintain market share have also been recognized as an important lesson from this example since it has necessitated consideration of a patent strategy whenever new forms (polymorphs, 


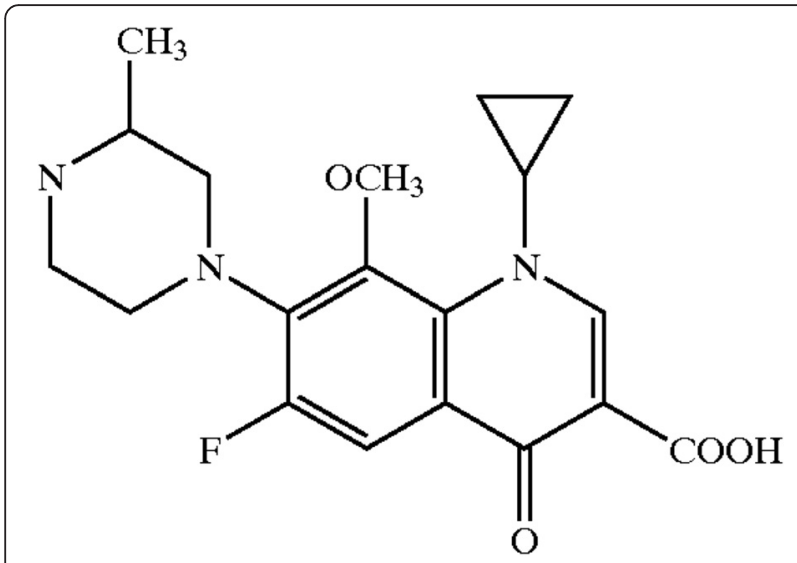

Fig. 10 Structure of gatifloxacin

hydrates, solvates, salts, cocrystals, amorphous solid dispersions, etc.) have been found during development.

While the initial discovery of a crystalline form during Phase 3 clinical trials would have normally been considered a "bad" scenario, the atorvastatin story has proven that after the extra work has been completed, a very "good" scenario and a successful product resulted.

\section{Gatifloxacin - crystalline form changes with a licensed compound}

Gatifloxacin (also known as AM-1155, CG5501, and BMS-206584) has been established as a fluoroquinoline broad-spectrum antibiotic (Fukuda et al. 1998) (Fig. 10). It was originally discovered by Kyorin Pharmaceuticals in the late 1980s as a hemihydrate that was recrystallized from methanol (Masuzawa et al. 1991). This crystalline form was found to be hygroscopic and resulted in poor tablet disintegration and dissolution. In the mid-1990s, a sesquihydrate was found by Kyorin with improved properties (Matsumoto et al. 1999). The compound was licensed to Bristol-Myers Squibb (BMS) in 1996 with two hydrated forms disclosed.

Initial clinical formulations at BMS utilized the sesquihydrate in a wet granulation process. The clinical batch failed specifications when a new crystal form was discovered in the batch. The new crystal form was confirmed as a pentahydrate (Raghaven et al. 2002), which was found to be less soluble and more stable in various formulations (wet granulations, dry blends, and aqueous suspensions). Issues with the initial clinical sesquihydrate formulation, as well as difficulty producing pure sesquihydrate material, had prompted crystallization studies to find a better understanding of the solid form landscape.

Crystallization studies using only ethanol, water, and various drying conditions resulted in 12 additional forms for gatifloxacin (Fig. 11) (Raghaven et al. 2002). These studies added considerable elements to the development timeline of the compound, including finding the forms, developing API processes for the desired forms, optimizing clinical formulations, and requalifying analytical

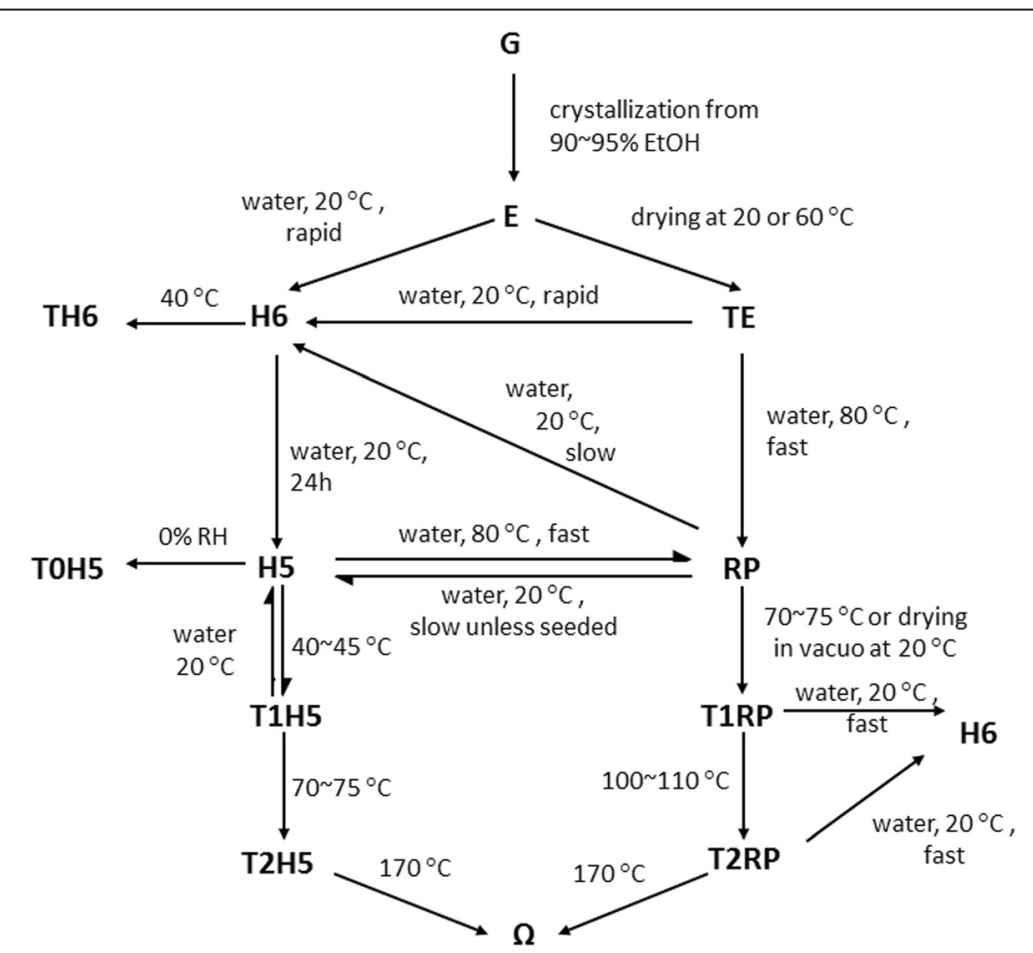

Fig. 11 Gatifloxacin crystalline forms from ethanaol, water, and various drying conditions (adapted from reference (Raghaven et al. 2002)) 
methods. While the pentahydrate exhibited superb physical properties for the API and formulation, it was also found to be less bioavailable compared to the sesquihydrate. This resulted in a switch back to the sesquihydrate form for the marketed tablet formulation Tequin ${ }^{\circ}$, approved in 1999 (Fish and North 2001). Potentially fatal blood sugar problems resulted in a blackbox warning for Tequin, as well as a subsequent removal of Tequin ${ }^{\circ}$ from the US and Canadian markets in 2006. The sesquihydrate was subsequently used in the production of ophthalmic solutions, Zymar ${ }^{\circ}$ and Zymaxid ${ }^{\circ}$. After the compound patent had expired in 2010, Apotex started to use the hemihydrate in their generic product.

Gatifloxacin has provided an example of multiple form changes throughout mid to late stage development. These changes created significant additional work around API crystallization development, formulation processing, analytical methods, and biological studies (i.e., bridging and bioequivalence studies). This case study has also demonstrated the criticality of due diligence for in-licensed compounds, including proper screening. Companies that in-license a compound should ask specific questions about the solid form studies that were performed to determine the scope of knowledge and inter-relationships between forms, and how the solid form landscape would impact the desired dosage form and development plan. For companies that out-license a compound, a solid form study targeted toward the most stable form, crystallization conditions, and formulation processes have resulted in a much stronger package.

While the initial package for gatifloxacin seemed straightforward with only two hydrated forms, it should be classified as an "ugly" scenario due to the solid form changes and additional studies.

\section{Lifecycle management}

Olanzapine - crystalline change from free acid to salt Olanzapine (Fig. 12), a Biopharmaceutics Drug Disposition Classification System (BDDCS) 2 drug (Benet et al. 2011) with poor solubility and high permeability, has been marketed towards treating schizophrenia. Olanzapine has been shown to exhibit a number of different crystalline forms including hydrates (Reutzel-Edens et al. 2003) and solvates (Cavallari et al. 2013). Form I has been deemed the most stable unsolvated form (Reutzel-Edens et al. 2003). A variety of dosage forms have been developed to target different patient populations. These products have included Zyprexa ${ }^{\circ}$ tablets (once a day oral tablets), Zyprexa Zydis ${ }^{\circ}$ orally disintegrating tablets (that can be taken without water), and Zyprexa Intra Muscular ${ }^{\circ}$ (rapid acting intramuscular injection). A combination capsule product with fluoxetine hydrochloride $(\mathrm{HCl})$ (Symbyax $^{\circ}$ ) was also launched when indications were expanded

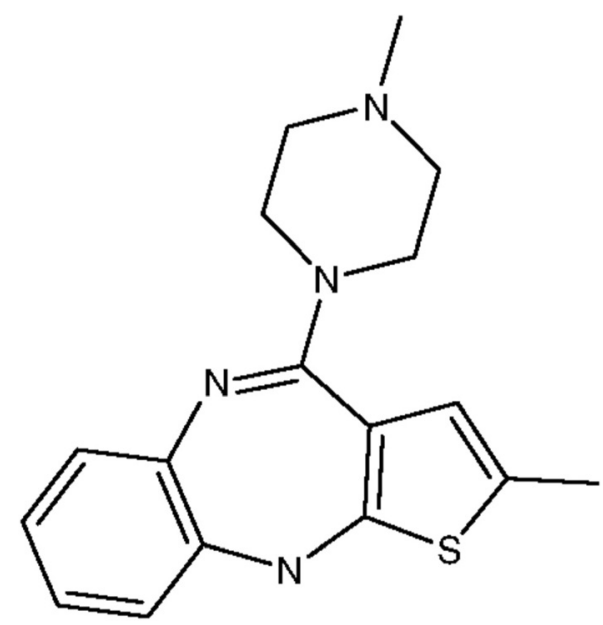

Fig. 12 Structure of olanzapine

to include treatments of bipolar disorder and resistance depression in its marketing.

A major issue with this patient group was compliance; as a result, a dosage form that lasted longer than once daily would have provided a significant benefit for the patients. To address this issue, researchers developed a long acting injection (LAI) using olanzapine pamoate monohydrate and sold as Zyprexa Relprevv in 2010 (Chue and Chue 2012). The pamoate salt was shown to be poorly soluble in aqueous media, and micron sized crystals were suspended in a diluent containing carboxymethylcellulose sodium, mannitol, polysorbate 80 , sodium hydroxide and/or hydrochloric acid for $\mathrm{pH}$ adjustment and water for injection (Zyprexa Relprevv Package Insert 2014). As a result, the salt slowly dissolved after injection into the muscle, resulting in an absorption of olanzapine systemically over a period of several weeks (Citrome 2009). The half-life of the pamoate salt became 30 days, in comparison to $33 \mathrm{~h}$ for an oral dose (Di Lorenzo and Brogli 2010). One injection has been noted to last three to four weeks, providing better efficacy and compliance for patients (Fig. 13) (Agency et al. 2015). The efficacy and tolerability profiles for the LAI were found to be the same as the oral formulation. The olanzapine Form II patent listed in the Orange Book (US 6960577) is set to expire in 2017. The olanzapine pamoate monohydrate patent listed in the Orange Book (US 6169084) has an expiry date of 2018 , which has given the LAI dosage form a year of extra patent coverage.

This case study has illustrated the advantages of using novel solid forms for innovative drug products. The change in solid form to a crystalline pamoate salt resulted in a less soluble salt, which has previously not been desired by researchers. However, in this case, the less soluble salt exhibited all the properties needed for 


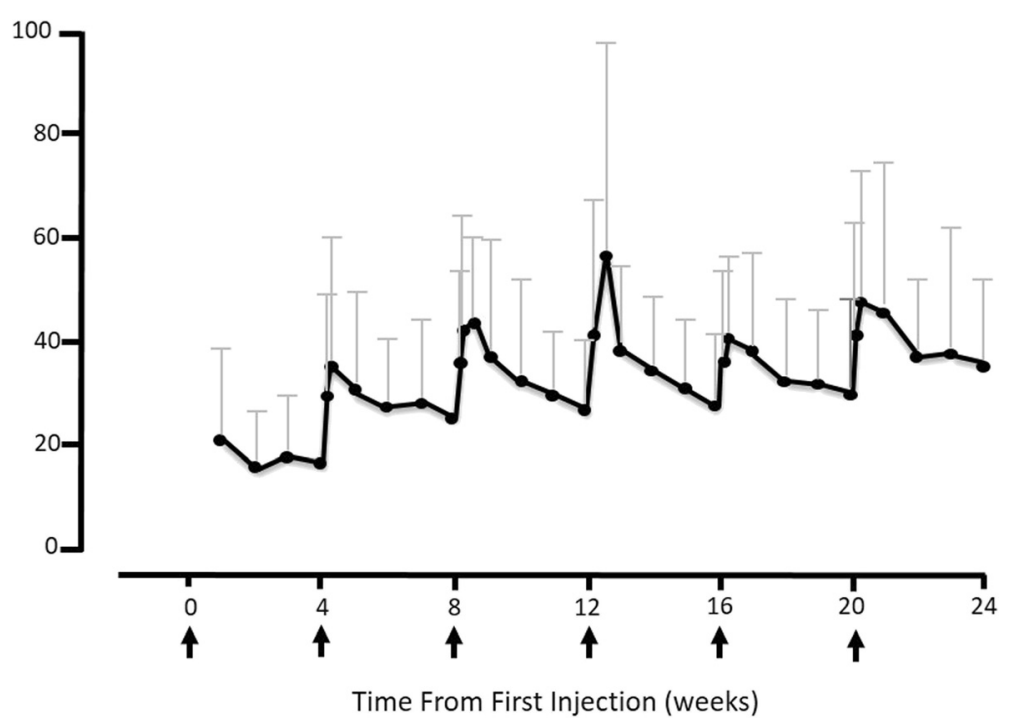

Fig. 13 Mean olanzapine plasma concentrations for the Multiple-Dose Group receiving 405 mg/4 weeks; arrows along x-axis indicate injections (adapted from reference (Agency et al. 2015))

an improved sustained release formulation. Rather than an oral dosage form, an intramuscular injection was produced to capitalize on the lower solubility. The result became a dosage form with good efficacy and superior compliance. Additionally, patent coverage around the new salt has also extended coverage for a year after the olanzapine free base expires.

\section{Oxybutynin- crystalline change from salt to free base}

Oxybutynin $\mathrm{HCl}$ (Fig. 14) has been recognized as a BDDCS I compound exhibiting high solubility and permeability (Benet et al. 2011). It has been used in a variety of marketed products for the treatment of overactive bladder (Gamble and Sand 2008). The first oral formulation from Hoechst Marion Roussel in 1975 was an immediate release tablet $\left(\right.$ Ditropan $\left.^{\circ}\right)$, which was dosed three times a day. The major side effect was dry mouth, which was the primary reason for patients discontinuing use (Sathyan et al. 2001). The side effect of dry mouth was caused by the metabolite desethyloxybutynin. The metabolite was reduced by developing a controlled release dosage form, which maintained a zero order release. This resulted in lower peak to trough variations in plasma levels and bypassed the pre-systemic metabolism and conversion to the active metabolite. Ditropan $\mathrm{XL}^{\bullet}$ was launched in 1999 using Alza's osmotic delivery (OROS) formulation approach, which reduced the severity of dry mouth side effects (Sathyan et al. 2001). This formulation approach also allowed one daily dose, as opposed to the original three daily doses, which was more convenient for the patient and helped improve patient compliance.
Another way to reduce the metabolite and side effects was to bypass the first pass metabolism using a different administration route. Watson launched an $\mathrm{Oxytrol}^{\circ}$ transdermal patch in 2003, which was designed to deliver oxybutynin over a three to four day interval. Reformulation into the patch required researchers to use the oxybutynin free base, instead of the hydrochloride salt, for better skin transport. Bypassing the oral delivery route significantly reduced the metabolite (Fig. 15), which resulted in minimal side effects and better patient compliance (Gamble and Sand 2008). In January 2013, an over-the-counter (OTC) patch was approved by the FDA for commercial use (http://www.fda.gov/ NewsEvents/Newsroom/PressAnnouncements/ucm336 815.htm. Accessed 2 March 2015).

This case study shows how a change in form and delivery route has not only reduced side effects, but also resulted in a more efficient and convenient drug product for the patient. The development of the patch required a change in form from the hydrochloride salt to free base, which enabled the drug to pass through the skin. Finding a different form to develop an improved

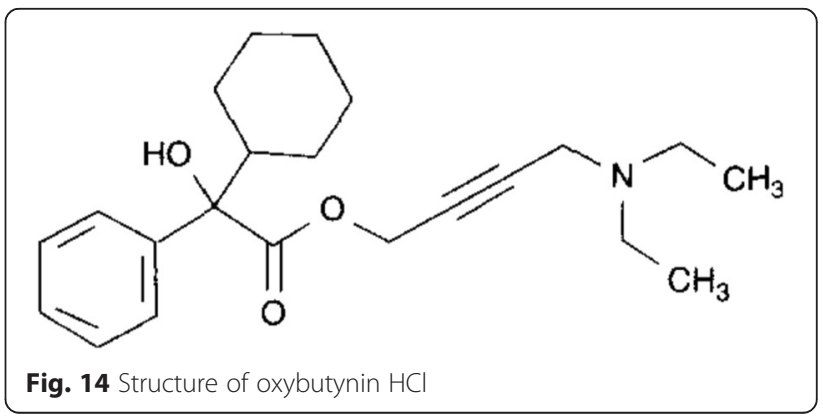


@ Oxybutynin $\quad$ N-desethyloxybutynin

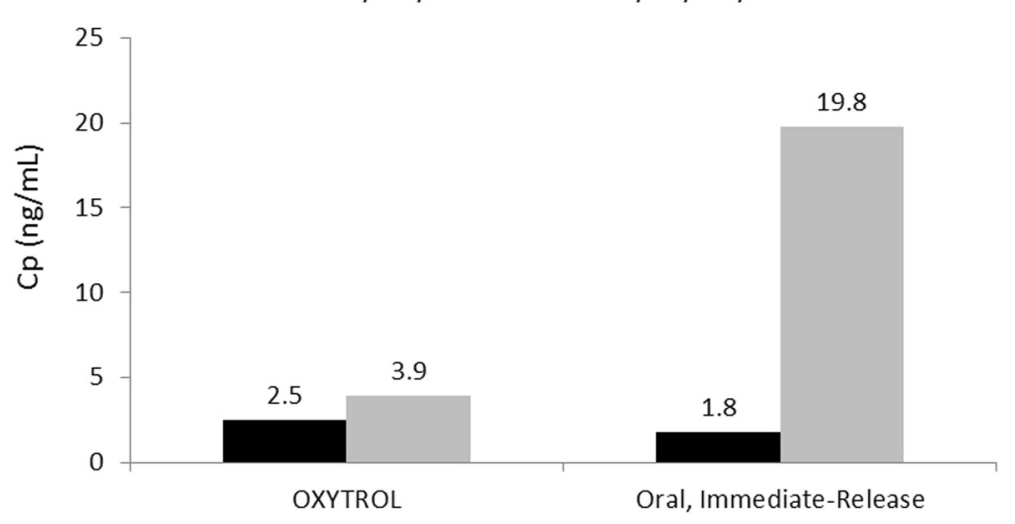

Fig. 15 Comparison of blood levels of oxybutynin and its metabolite, $\mathrm{N}$-desethyloxybutynin, showing that the patch resulted in significantly lower levels of the metabolite, which reduced the dry mouth side effect, compared to the oral immediate release formulation (Oxytrol Package Insert. (available at http://pi.watson.com/data_stream.asp?product_group=1295\&p=pi\&language=E. Accessed 2 March 2015)

drug product required an understanding of the properties needed for a particular dosage form and thorough characterization of various forms. This change in form could include a polymorph, free acid/base, salt, cocrystal, or amorphous solid dispersion. Specific counterions or guest molecules would need to be considered for certain delivery routes, such as dermal, ophthalmic, intravenous, or intramuscular formulations (Paulekuhn et al. 2007). Determining the issues with current products and finding creative solutions using form and formulation to produce an improved product has been recognized as a true "win-win" in lifecycle management.

\section{Conclusions}

The case studies in this manuscript have been presented to show why it has been critical to characterize, understand, and monitor the solid form in all stages of drug discovery and development. While these case studies have been presented in the literature, there have been even "uglier" cases that have not been published. It is important for researchers to realize that form selection is not a unit operation, but an integral part of the entire drug development process, with no clear beginning or end; instead, there should be continuous scrutiny and monitoring as a candidate progresses from discovery to development to market and beyond.

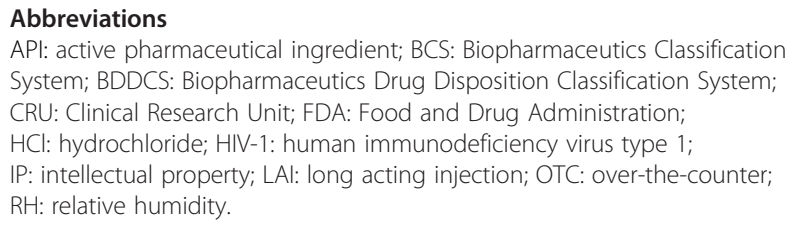

Abbreviations

API: active pharmaceutical ingredient; BCS: Biopharmaceutics Classification System; BDDCS: Biopharmaceutics Drug Disposition Classification System; CRU: Clinical Research Unit; FDA: Food and Drug Administration; $\mathrm{HCl}$ : hydrochloride; HIV-1: human immunodeficiency virus type 1; IP: intellectual property; LAI: long acting injection; OTC: over-the-counter; $\mathrm{RH}$ : relative humidity.

\section{Competing interests}

The authors declare that they have no competing interests.

\section{Authors' contributions}

Both AN and RW contributed to the information gathering and writing of the manuscript. All authors read and approved the final manuscript.

\section{Authors' information}

Ann Newman

AN is currently a pharmaceutical consultant at Seventh Street Development Group and the Vice President of Scientific Development at Crystal Pharmatech, with over 25 years of large pharma and contract research experience. For ten years, AN performed characterization studies on a wide range of pharmaceutical systems at Bristol-Meyers Squibb, covering drug substance and product scale-up from late drug discovery to launch and manufacturing. After that, she became Vice President of Materials Science at SSCl, Inc., overseeing characterization of API and drug product samples, crystallization and polymorph screens, salt selections, quantitative assays, amorphous projects and problem solving for the pharmaceutical industry. As Vice President of Research and Development at Aptuit, AN instituted a company-wide R\&D initiative over six global sites and covering areas such as API, preclinical (toxicology, safety, pharmacokinetics), formulation, solids, analytical, clinical packaging, and regulatory. She currently holds an adjunct faculty position in Industrial and Physical Pharmacy at Purdue University and is a collaborator on over 50 publications, 90 technical presentations, and 60 webinars.

Robert Wenslow

RW is currently Vice President of Business Development for Crystal Pharmatech. Prior to joining Crystal Pharmatech, RW spent 14 years at Merck \& Co. His group supported, on average, 30 drug development projects per year. They contributed to salt and polymorph selection, crystallization development and optimization, preparation of registration documents, and specification setting in the area of solid-state support for both bulk drug substance and drug product. RW received his Ph.D. in Analytical Chemistry from The Pennsylvania State University; has presented as invited lecturer at over 15 conferences; has published over 25 peer reviewed journal articles, and is co-author on over 10 patents.

Received: 9 November 2015 Accepted: 17 February 2016

Published online: 25 February 2016

\section{References}

European medicines Agency, Assessment Report for Zypadhera, Doc Ref: 608654/ 2008. p 31. (http://www.ema.europa.eu/docs/en_GB/document_library/ EPAR_-_Public_assessment_report/human/000890/WC500054428.pdf. Accessed 23 Feb 2016)

Aungst BJ, Nguyen H, Taylor NJ, Bindra DS (2002) Formulation and food effects on the oral absorption of a poorly water soluble, highly permeable antiretroviral. J Pharm Sci 91:1390-1395

Benet LZ, Brocatelli F, Oprea TI (2011) BDDCS applied to over 900 drugs. AAPS J 13:519-547 
Briggs CA, Jennings RA, Wade R, Harasawa K, Ichikawa S, Minohara K, Nakagawa $S$ (1999) Crystalline [R-( $\left.R^{*}, R^{*}\right]$-2-(4-difluorophenyl)- $\beta, \delta$-dihydroxy-5-(1methylehtyl)-3-phenyl-4-[phenylamino)carbonyl]-1H-pyrrole-1-heptanoic acid hemi calcium salt (atorvastatin). US Patent 5,969,156, 19 Oct 1999

Byrn SR, Coates DA, Gushurst KS, Krzyzaniak JF, Li ZJ, Morrison HG, Park A, Vlahova PI (2003) Crystalline Forms of $\left[R-\left(R^{*}, R^{*}\right]-2-(4-d i f l u o r o p h e n y l)-\beta, \delta\right.$ dihydroxy-5-(1-methylehtyl)-3-phenyl-4-[phenylamino)carbonyl]-1H-pyrrole-1heptanoic acid hemi calcium salt (2:1). US Patent 6,605,729, 12 Aug 2003

Campeta AM, Chekal BP, Abramov YA, Meenan PL, Henson MJ, Shi B, Singer RA, Horspool KR (2010) Development of a targeted polymorph screening approach for a complex polymorphic and highly solvating API. J Pharm Sci 99:3874-3886

Cavallari C, Santos BP, Fini A (2013) Olanzapine solvates. J Pharm Sci 102:4046-4056

Chue P, Chue J (2012) A review of olanzapine pamoate. Expert Opin Pharmacother 13:1661-1670

Citrome L (2009) Olanzapine pamoate: a stick in time? Int J Clin Pract 63:140-150

Crixivan Package Insert. (available at http://www.merck.com/product/usa/pi_ circulars/c/crixivan/crixivan_pi.pdf. Accessed 23 Feb 2016)

Desikan S, Parsons RL, Davis WP, Ward JE, Marshall WJ, Toma PH (2005) Process development challenges to accommodate a late-appearing stable polymorph: a case study on the polymorphism and crystallization of a fasttrack drug development compound. Org Proc Res Dev 9:933-942

Di Lorenzo R, Brogli A (2010) Profile of olanzapine long-acting injection for the maintenance treatment of adult patients with schizophrenia. Neuropsychiatr Dis Treat 6:573-581

Dunitz JD, Bernstein J (1995) Disappearing polymorphs. Acc Chem Res 28:193-200

Fish DN, North DS (2001) Gatifloxacin, an advanced 8-methoxy fluoroquinolone. Pharmacotherapy 21:35-39

Fukuda H, Hori S, Hiramatsu K (1998) Antibacterial activity of gatifloxacin (AM1155, CG5501, BMS-206584), a newly developed fluoroquinolone, against sequentially acquired quinolone-resistant mutants and the nor $A$ transformant of Staphylococcus aureus. Antimicrob Agents Chemother 42: 1917-1922

Gamble T, Sand P (2008) Patient perspectives in the management of overactive bladder, focus on transdermal oxybutynin. Patient Prefer Adherence 2:349-356

FDA approves over-the-counter Oxytrol for Women to treat overactive bladder. http://www.fda.gov/NewsEvents/Newsroom/PressAnnouncements/ ucm336815.htm. Accessed 23 Feb 2016

Lie JJ (2009) Triumph of the Heart. The Story of Statins. Oxford University Press, New York

Lin JH (1999) Role of pharmacokinetics in the discovery and development of indinavir. Adv Drug Deliv Rev 39:33-49

Lin JH, Ostovic D, Vacca JP (1998) Chapter 11. The integration of medicinal chemistry, drug metabolism, and pharmaceutical research and development in drug discovery and development. The story of Crxivan ${ }^{\oplus}$, an HIV protease inhibitor. In: Borchardt RT, Freidinger RM, Sawyer TK, Smith PL (eds) Integration of Pharmaceutical Discovery and Development: Case Studies. Plenum Press, New York

Lui CY, Ostovic D, Katdare AV,Stemach C (2003) Dry granulation formulation for an HIV protease inhibitor. US Patent 6,645,961, 11 Nov 2003

Masuzawa K, Suzue S, Hirai K, Ishizaki T (1991) 8-Alkoxyquinolonecarboxylic acid and salts thereof. US patent 5,043,450, 27 Aug 1991

Matsumoto T, Hara M, Miyashita K, Kato Y (1999) 8-Alkoxyquinolonecarboxylic acid hydrate with excellet stability and process for producing the same. US patent 5,880, 283, 9 Mar 1999

Newman AW, Byrn SR (2003) Solid-state analysis of the active pharmaceutical ingredient in drug products. Drug Deliv Today 8:898-905

Oxytrol Package Insert. (available at http://pi.watson.com/data_stream. asp?product_group $=1295 \& p=$ pi\&language $=E$. Accessed 23 Feb 2016)

Paulekuhn GS, Dressman JB, Saal C (2007) Trends in active pharmaceutical ingredient salt selection based on analysis of the orange book database. Jed Chem 50:6665-6672

Pfizer Citizen Petition. Docket no 2005P-0452. 2005. (available at http://www.fda. gov/ohrms/dockets/dockets/05p0452/05p-0452-cp00001-01-vol1.pdf. Accessed 23 Feb 2016)

Raghaven KS, Ranadive SA, Gougoutas JZ, DiMarco JD, Parker WL, Davidovich M, Newman A (2002) Gatifloxacin pentahydrate. US patent 6,413, 969, 2 Jul 2002

Reutzel-Edens SM, Bush JK, Magee PA, Stephenson GA, Byrn SR (2003) Anhydrates and hydrates of olanzapine: crystallization, solid-state characterization, and structural relationships. Cryst Growth Des 3:897-907
Sathyan G, Chancellor MB, Gupta SK (2001) Effect of OROS ${ }^{\circledast}$ controlled-release delivery on the pharmacokinetics and pharmacodynamics of oxybutynin chloride. Br J Clin Phrmacol 52:409-417

Staszewski S, Morales-Ramirez J, Tashima KT, Rachlis A, Skiest D, Stanford J, Stryker R, Johnson P, Labriola DF, Farina D, Manion DJ, Ruiz NM (1999) Efavirenz plus zidovudine and lamivudine, efavirenz plus indinavir and indinavir plus zidovudine and lamivudine in the treatment of HIV-1 in adults. New Engl J Med 341:1865-1873

Tesslor L, Aronhime J, Lifshitz-Liron R, Maidan-Hanoch D, Hasson N (2003) Crystal forms of atorvastatin hemi-calcium and processes for their preparation as well as novel processes for preparing other forms. US Patent 7,256,212, 14 Aug 2007

Tully W (2003) Factory scale process for producing crystalline atorvastatin trihydrate hemi calcium salt. US patent 6,600,051 B2, 29 Jul 2003

Van Der Schaaf PA, Blatter F, Szelagiewicz M, Schoning K-U (2009) Crystalline Forms of Atorvastatin. US Patent 7,538,136, 26 May 2009

Wu C-Y, Benet LZ (2005) Predicting drug disposition via application of BCS: transport/absorption/elimination interplay and development of a biopharmaceutics drug disposition classification system. Pharm Res 22:11-23

Yeh KC, Deutsch PJ, Haddix H, Hesney M, Hoagland V, Ju WD, Justice SJ, Osborne B, Sterrett AT, Stone JA, Woolf E, Waldman S (1998) Single-dose pharmacokinetics of indinavir and the effect of food. Antimicrob Agents Chemother 42:332-338

Zyprexa Relprevv Package Insert December 2014. (available at http://pi.lilly.com/ us/zyprexa_relprevv.pdf. Accessed 23 Feb 2016)

\section{Submit your manuscript to a SpringerOpen ${ }^{\circ}$ journal and benefit from:}

- Convenient online submission

- Rigorous peer review

- Immediate publication on acceptance

- Open access: articles freely available online

- High visibility within the field

- Retaining the copyright to your article

Submit your next manuscript at $>$ springeropen.com 